\title{
Nuclear magnetic resonance and mass spectrometry-based milk metabolomics in dairy cows during early and late lactation
}

\author{
M. S. Klein, ${ }^{* 1}$ M. F. Almstetter, ${ }^{* 1}$ G. Schlamberger, $\dagger$ N. Nürnberger, ${ }^{*}$ K. Dettmer, ${ }^{*}$ P. J. Oefner, ${ }^{*}$ H. H. D. Meyer, $\dagger$ \\ S. Wiedemann, $\dagger^{2}$ and $W$. Gronwald ${ }^{* 2}$ \\ *Institute of Functional Genomics, University of Regensburg, Josef-Engert-Str. 9, 93053 Regensburg, Germany \\ †Physiology Weihenstephan, Technische Universitaet Muenchen, Weihenstephaner Berg 3, 85354 Freising-Weihenstephan, Germany
}

\begin{abstract}
Milk production in dairy cows has dramatically increased over the past few decades. The selection for higher milk yield affects the partitioning of available nutrients, with more energy being allocated to milk synthesis and less to physiological processes essential to fertility and fitness. In this study, the abundance of numerous milk metabolites in early and late lactation was systematically investigated, with an emphasis on metabolites related to energy metabolism. The aim of the study was the identification and correlation of milk constituents to the metabolic status of the cows. To investigate the influence of lactation stage on physiological and metabolic variables, 2 breeds of different productivity were selected for investigation by high-resolution nuclear magnetic resonance spectroscopy and gas chromatography-mass spectrometry. We could reliably quantify 44 different milk metabolites. The results show that biomarkers such as acetone and $\beta$-hydroxybutyrate are clearly correlated to the metabolic status of the individual cows during early lactation. Based on these data, the selection of cows that cope well with the metabolic stress of early lactation should become an option.
\end{abstract}

Key words: milk metabolomics, nuclear magnetic resonance, mass spectrometry

\section{INTRODUCTION}

Measurement of selected milk constituents to monitor the udder health or the metabolic status of cows has attracted much attention in dairy research and is widely used on dairy farms. Milk SCC and $N$-acetyl- $\beta$ D-glucosaminidase activity are well-known indicators of intramammary infections (Pyorala, 2003). Furthermore, the biochemical milk profile has been related to the

\footnotetext{
Received July 13, 2009.

Accepted December 2, 2009.

${ }^{1}$ These authors contributed equally.

${ }^{2}$ Corresponding authors: steffi.wiedemann@wzw.tum.de and wolfram.gronwald@klinik.uni-regensburg.de
}

health status of the cow and, in particular, to imbalances during early lactation (Duffield et al., 2009). Ketone bodies such as acetone, acetoacetate, and BHBA in milk are biomarkers for subclinical ketotic conditions (Geishauser et al., 2000; Enjalbert et al., 2001). For example, BHBA concentrations $\geq 0.10 \mathrm{mmol} / \mathrm{L}$ indicate subclinical ketosis yielding a sensitivity, specificity, and a positive and negative predictive value of $69,95,75$, and $93 \%$, respectively. Enjalbert et al. (2001), on the other hand, proposed thresholds for milk acetone and BHBA of 0.16 and $0.07 \mathrm{mmol} / \mathrm{L}$, respectively. On the basis of the close interaction between blood circulation and milk secretion, changes in additional milk metabolites that have yet to be defined can be assumed to reflect the metabolic and health conditions of the cow and the mammary gland.

High-resolution nuclear magnetic resonance (NMR) spectroscopy is a powerful tool for the analysis of physiological fluids that contain complex mixtures of organic molecules (Lindon et al., 2006). Requiring little sample preparation, NMR allows the direct and reliable determination of analytes in biological specimens (Wishart, 2008). The one drawback of NMR is its limited detection sensitivity compared with mass spectrometry (MS). The latter also offers the advantage of excellent selectivity when operated in selected ion monitoring mode. Coupled to gas chromatography (GC), a highresolution separation technique, hundreds of metabolites can be identified and quantified in a single run (Almstetter et al., 2009).

Previously, both NMR (Belloque and Ramos, 2002; $\mathrm{Hu}$ et al., 2007) and GC-MS (Toso et al., 2002; Boudonck et al., 2009) have been applied successfully to the analysis of compounds in commercially available milk samples. Here, NMR and GC-MS were applied to the determination of a total of 44 milk compounds in milk specimens obtained from individual dairy cows of 2 different breeds during early and late lactation, with an emphasis on metabolites related to energy metabolism. The ultimate aim of the study was to identify the compounds that are highly correlated to the metabolic status of the indivdual animals. 
Table 1. Ingredients and chemical composition of the partial mixed rations $^{1}$

\begin{tabular}{lcc}
\hline Item & Farm 1 & Farm 2 \\
\hline Ingredient (\%) & & \\
Corn silage & 60 & 59 \\
Grass silage & 24 & 27 \\
Hay & 4 & 3 \\
Concentrate & $11^{2}$ & $11^{3}$ \\
Mineral mix & $1^{4}$ & - \\
Chemical composition & 43.7 & 43.7 \\
DM (\%) & 12.9 & 13.2 \\
CP (\% of DM) & 18.8 & 18.9 \\
Crude fiber (\%) & 14.3 & 14.3 \\
Utilizable CP (\%) & 1.65 & 1.65 \\
NE & (Mcal/kg) &
\end{tabular}

${ }^{1}$ Concentrates were additionally fed according to milk yield.

${ }^{2}$ Composition: corn gluten $18.4 \%$, turnips molasses chips $13.8 \%$, wheat $10.0 \%$, triticale $10.0 \%$, rape cake $10.0 \%$, maize $8.8 \%$, malt germ $6.0 \%$, grain distillation residual (ProtiGrain Crop Energies AG, Mannheim, Germany) $5 \%$, rape extraction grist $5 \%$, rumen protected rape extraction grist $5 \%$, palm corn cake $3.3 \%$, soy extraction grist $2.8 \%$, sodium bicarbonate $1.0 \%$, calcium bicarbonate $0.99 \%$, plant oil (palm coconut) $0.40 \%$.

${ }^{3}$ Composition: rape cake $20 \%$, soy extraction grist $24 \%$, barley $21 \%$, wheat $18.7 \%$, maize $10 \%$, sodium bicarbonate $0.8 \%$, calcium bicarbonate $1 \%$, urea $1 \%$.

${ }^{4}$ Ingredients: calcium $14 \%$, sodium $10.0 \%$, phosphorous $5.0 \%$, magnesium $5.0 \%$.

\section{MATERIALS AND METHODS}

\section{Collection of Milk Samples}

Morning milk specimens were collected at 2 research farms near Munich, Germany, from cow breeds representing different milk production levels. At the research farm Veitshof (Freising, Germany; farm 1), milk samples were collected from highly productive Brown Swiss cows with an average 305-d milk yield of 9,200 $\mathrm{kg}$ in early (average \pm SD: $42.8 \pm 25.3$ DIM; $\mathrm{n}=27$ ), mid (143.4 \pm 21.5 DIM; $\mathrm{n}=7)$, and late $(345.7 \pm 159.2 \mathrm{DIM} ; \mathrm{n}=$ 24) lactation. At the Bavarian State Research Center for Agriculture (Grub, Germany; farm 2), milk samples of Simmental cows with an average 305-d milk yield of $8,300 \mathrm{~kg}$ in early (DIM $25.0 \pm 12.3 ; \mathrm{n}=28$ ) and late (DIM $261.8 \pm 41.3 ; \mathrm{n}=20$ ) lactation were collected. All cows were offered ad libitum a partial TMR based on corn and grass silage. Concentrates were offered according to milk yield. Details about the different diets are given in Table 1. For technical reasons, AA composition of the ration was not determined. However, it has been shown previously that the fractional efficiencies of converting portal vein-absorbed individual essential AA into milk protein ranged from 0.42 to 0.68 (Blouin et al., 2002). Thereby, the liver changes the profile of AA available to the mammary gland relative to the amount absorbed from the gut.

One aliquot of the collected milk samples was analyzed for milk protein, fat, lactose, urea, and $\mathrm{pH}$ by
MilkoScan FT 6000 and for SCC by Fossomatic-FC (MPR Bayern e.V., Wolnzach, Germany). The second aliquot was defatted by centrifugation for $15 \mathrm{~min}$ at $3,000 \times g$ at a temperature of $4^{\circ} \mathrm{C}$, and skim milk was immediately stored at $-20^{\circ} \mathrm{C}$ until analysis.

\section{Sample Preparation for NMR Analysis}

Milk samples were thawed, thoroughly shaken, and ultra-filtered employing Amicon Ultra-4 centrifugal filter units (Millipore, Billerica, MA) with a molecular weight cutoff of $10 \mathrm{kDa}$ that were spun for $60 \mathrm{~min}$ at $4,000 \times g$ in a swing-bucket rotor at $22^{\circ} \mathrm{C}$. Filtration was necessary to remove large biomolecules, such as proteins, from the samples. Tests without filtration showed broad background signals that severly hampered metabolite quantification. In addition, complex formation between the used NMR reference compound and proteins was observed, which resulted in a considerably diminished reference signal. The used NMR reference compound was 3-trimethylsilyl-2,2,3,3-tetradeuteropropionate (TSP; Sigma-Aldrich, Taufkirchen, Germany). Four hundred microliters of ultrafilrate was then mixed with $200 \mu \mathrm{L}$ of $0.1 \mathrm{~mol} / \mathrm{L}$ of phosphate buffer ( $\mathrm{pH} 7.4$ ) and $50 \mu \mathrm{L}$ of $29.02 \mathrm{mmol} / \mathrm{L}$ of TSP in deuterium oxide as internal standard. One hundred milliliters of phosphate buffer ( $\mathrm{pH} 7.4$ ) was prepared by adding $8.02 \mathrm{~mL}$ of $1 \mathrm{~mol} / \mathrm{L}$ of aqueous $\mathrm{K}_{2} \mathrm{HPO}_{4}$ solution to $1.98 \mathrm{~mL}$ of $1 \mathrm{~mol} / \mathrm{L}$ of aqueous $\mathrm{KH}_{2} \mathrm{PO}_{4}$ solution and filling up to $100 \mathrm{~mL}$ with pure water. Finally, $30 \mathrm{mg}$ of boric acid was added to prevent bacterial growth.

\section{NMR Spectroscopy}

The NMR experimental conditions and algorithms used for data analysis have been described recently (Gronwald et al., 2008). Briefly, NMR experiments were carried out on a Bruker Avance III $600 \mathrm{MHz}$ spectrometer (Bruker BioSpin GmbH, Rheinstetten, Germany) employing a triple-resonance $\left({ }^{1} \mathrm{H},{ }^{13} \mathrm{C},{ }^{31} \mathrm{P}\right.$, ${ }^{2} \mathrm{H}$ lock) cryogenic probe equipped with z-gradients and the SampleJet automatic sample changer. For each sample, the probe was automatically locked, tuned, matched, and shimmed. A standard-shim file optimized for milk was used as a starting point for the automated shimming procedure. All spectra were measured at 298 $\mathrm{K}\left(25^{\circ} \mathrm{C}\right)$ after equilibration in the magnet for $300 \mathrm{~s}$. One-dimensional (1D) ${ }^{1} \mathrm{H}$ and 2-dimensional (2D) ${ }^{1} \mathrm{H}$ ${ }^{13} \mathrm{C}$ heteronuclear single quantum coherence (HSQC) spectra were automatically collected without spinning. One-dimensional ${ }^{1} \mathrm{H}$ NMR spectra were obtained using a 1D nuclear Overhauser enhancement spectroscopy (NOESY) pulse sequence. The solvent signal was suppressed by presaturation during relaxation and mix- 
ing time and additional spoil gradients. A total of 128 scans were collected for each spectrum into 65,536 data points using a relaxation delay of $4 \mathrm{~s}$, an acquisition time of $2.66 \mathrm{~s}$, and a mixing time of $0.01 \mathrm{~s}$. Throughout the paper, ppm values are used to indicate the position (chemical shift) of a signal in a spectrum. In NMR spectroscopy, chemical shifts are measured in parts per million relative to a reference resonance signal from a standard molecule. A ppm value is calculated as the difference in resonance frequency (measured in $\mathrm{Hz}$ ) between the nucleus of interest and the reference nucleus divided by the operating frequency of the magnet (measured in $\mathrm{Hz}$ ). Because the resulting value is rather small, it is multiplied by 1 million; therefore, the name parts per million. The spectral width was set to $20 \mathrm{ppm}$ for each 1D spectrum, and 4 dummy scans were performed before each measurement. Spectra were automatically Fourier transformed and phase corrected, applying a line broadening of $0.3 \mathrm{~Hz}$ and zero-filling to 131,072 data points. A flat baseline was obtained by using the baseopt option of TopSpin2.1 (Bruker BioSpin GmbH), which performs a correction of the first points of the free-induction decay (FID).

Water suppression was achieved for the $2 \mathrm{D}{ }^{1} \mathrm{H}_{-}{ }^{13} \mathrm{C}$ HSQC spectra using presaturation during the relaxation delay. A total of $2,048 \times 128$ data points were collected for each $2 \mathrm{D}$ spectrum using 8 scans per increment, a relaxation delay of $3 \mathrm{~s}$, an acquisition time of $0.14 \mathrm{~s}$, and 16 dummy scans. These settings led to a total acquisition time of 56 min per spectrum. The spectral widths were set to $12 \mathrm{ppm}$ and $165 \mathrm{ppm}$ in the proton and carbon dimensions, respectively. One highresolution $2 \mathrm{D}{ }^{1} \mathrm{H}_{-}{ }^{13} \mathrm{C}$ HSQC spectrum was acquired for initial assignment of the metabolites. These assignments were further validated using long-range proton-carbon couplings obtained from a $2 \mathrm{D}^{1} \mathrm{H}^{13} \mathrm{C}$ heteronuclear multiple bond correlation spectrum. Two-dimensional spectra were semiautomatically processed employing a $90^{\circ}$ shifted squared sine-bell window function in both dimensions. In the indirect carbon dimension, increased resolution was obtained by doubling the number of data points before Fourier transform using complex forward linear prediction. All 2D spectra were manually phase corrected, and a polynomial baseline correction was applied excluding the region around the water artifact. All 1D and 2D spectra were chemical shift referenced relative to the TSP signal.

\section{Initial NMR Metabolite Assignment}

Initial metabolite assignment was performed manually as described in Gronwald et al. (2008). A summary of the obtained chemical shift data are provided in Table 2 . The chemical shift information of each identified metabolite signal was stored in a so-called knowledge base to guide the quantification process of the milk metabolites. To define the regions where the individual metabolite signals in a series of measured spectra are expected, individual chemical shift ranges were specified for each metabolite signal by manually analyzing interspectra chemical shift variations in a subset of the measured spectra. Depending on the analyzed type of spectrum, individually optimized chemical shift ranges were determined for each metabolite. In addition, the knowledge base describes the individual signals of a compound in terms of multiplet patterns, coupling constants, relative intensities, and masses. Coupling values with appropriate error bounds were obtained by analyzing the pure reference compound spectra together with the experimentally measured spectra of our series. Note that multiplet patterns caused by J-couplings were observable only in the 1D spectra. Overlapping signals located in crowded regions of the real milk spectra were excluded from the quantification process; especially in the region close to the intensive lactose signals, considerable overlap was present in both $1 \mathrm{D}$ and $2 \mathrm{D}$ spectra.

\section{Automated NMR Analysis}

The next steps of the analysis were performed with the Analytical Profiler module of AMIX 3.9 (Bruker BioSpin GmbH). The $1 \mathrm{D}{ }^{1} \mathrm{H}$ and $2 \mathrm{D}{ }^{1} \mathrm{H}_{-}{ }^{13} \mathrm{C}$ HSQC spectra corresponding to the series of milk specimens measured were automatically peak-picked. Using the information stored in the knowledge base, metabolite signals were identified and integrated. Multiplet information stored in the knowledge base was used in the integration process of $1 \mathrm{D}$ spectra to ensure that only the desired signals within the specified chemical shift ranges were integrated. In addition, a peak-fitting routine newly implemented in AMIX 3.9 was used to obtain accurate integrals even in regions with moderate signal overlap. Multiplet information was not applicable for $2 \mathrm{D}$ spectra. Here, information from the reference compound spectra database, such as the expected number of signals in a specific region, was used instead. Next, relative integrals with respect to the reference TSP signal were calculated for the individual metabolite signals. The use of relative integrals automatically corrects for machine-dependent sensitivity variations between experiments and has the additional advantage that calibration curves have to be determined only once. Finally, in-house routines were used for absolute quantification, employing individual calibration curves for each metabolite signal. Standard stock solutions were serially diluted for this purpose to yield final concentrations of $9,000,4,500,2,250,1,125,562.5,281.3,140.6$, $70.3,35.2,17.6$, and $8.8 \mu \mathrm{mol} / \mathrm{L}$, and the correspond- 
Table 2. Chemical shift values for the metabolite signals used for compound identification and quantification by high-resolution 1-dimensional ${ }^{1} \mathrm{H}$ and 2 -dimensional ${ }^{1} \mathrm{H}_{-}{ }^{13} \mathrm{C}$ heteronuclear single quantum coherence spectra

\begin{tabular}{|c|c|c|c|c|}
\hline Compound & Assignment & ${ }^{1} \mathrm{H}$ Chemical shift & ${ }^{13} \mathrm{C}$ Chemical shift & $\mathrm{Use}^{1}$ \\
\hline Acetate & $\mathrm{CH}_{3}$ & 1.92 & 25.8 & $q$ \\
\hline Acetone & $\mathrm{CH}_{3}$ & 2.24 & 32.7 & $q$ \\
\hline Alanine & $\mathrm{CH}$ & 3.79 & 53.4 & 1 \\
\hline Alanine & $\mathrm{CH}_{3}$ & 1.48 & 18.9 & $q$ \\
\hline Betaine & $\mathrm{CH}_{2}$ & 3.90 & 68.7 & $\mathrm{q}$ \\
\hline Betaine & $\mathrm{CH}_{3}$ & 3.26 & 56.0 & q \\
\hline Carnitine & $3 * \mathrm{CH}_{3}$ & 3.21 & 56.1 & - \\
\hline Carnitine & $\mathrm{CH}_{2}$ & 2.44 & 44.8 & $q$ \\
\hline Carnitine & $\mathrm{CH}_{2}^{2}$ & 3.43 & 72.6 & $\underline{1}$ \\
\hline Carnitine & $\mathrm{CH}$ & 4.57 & 66.3 & - \\
\hline Choline & $3 * \mathrm{CH}_{3}$ & 3.18 & 56.1 & - \\
\hline Choline & $\mathrm{CH}_{2}$ & 4.06 & 58.1 & $q$ \\
\hline Choline & $\mathrm{CH}_{2}$ & 3.51 & 69.9 & $q$ \\
\hline Creatinine & $\mathrm{CH}_{2}$ & 4.06 & 59.0 & $q$ \\
\hline Creatinine & $\mathrm{CH}_{3}$ & 3.05 & 32.8 & $\mathrm{q}$ \\
\hline Ethanolamine & $0-\mathrm{CH}_{2}$ & 3.83 & 60.3 & $q$ \\
\hline Ethanolamine & $\mathrm{N}-\mathrm{CH}_{2}$ & 3.15 & 44.0 & $q$ \\
\hline D-Galactose $\alpha$ & $\mathrm{CH}$ & 4.07 & 72.8 & $q$ \\
\hline D-Galactose $\alpha$ & $\mathrm{CH}$ & 3.81 & 70.9 & - \\
\hline D-Galactose $\beta$ & $\mathrm{CH}$ & 4.57 & 98.8 & $q$ \\
\hline D-Galactose $\beta$ & $\mathrm{CH}$ & 3.49 & 74.4 & $\mathrm{q}$ \\
\hline Glycerophosphocholine & $\mathrm{CH}_{2}$ & 4.32 & 61.7 & $\mathrm{q}$ \\
\hline Glycerophosphocholine & $\mathrm{CH}_{2}$ & 3.65 & 67.8 & $q$ \\
\hline Glycine & $\mathrm{CH}_{2}$ & 3.57 & 44.2 & $\mathrm{q}$ \\
\hline BHBA & $\mathrm{CH}_{3}$ & 1.20 & - & $q$ \\
\hline Lactate & $\mathrm{CH}_{3}$ & 1.32 & 22.1 & $\mathrm{q}$ \\
\hline Lactate & $\mathrm{CH}$ & 4.11 & 70.9 & $q$ \\
\hline D-Lactose (total) & $\mathrm{CH}$ & 4.45 & 105.0 & $\mathrm{q}$ \\
\hline D-Lactose (total) & $\mathrm{CH}$ & 3.73 & 77.6 & $\mathrm{q}$ \\
\hline D-Lactose (total) & $\mathrm{CH}$ & 3.94 & 71.0 & $\mathrm{q}$ \\
\hline D-Lactose (total) & $\mathrm{CH}$ & 3.54 & 73.4 & - \\
\hline D-Lactose (total) & $\mathrm{CH}$ & 3.67 & 74.9 & - \\
\hline D-Lactose (total) & $\mathrm{CH}_{2}$ & 3.78 & 63.4 & - \\
\hline D-Lactose $\alpha$ & $\mathrm{CH}^{2}$ & 5.23 & 94.2 & $q$ \\
\hline D-Lactose $\alpha$ & $\mathrm{CH}_{2}$ & 3.88 & 62.3 & $\mathrm{q}$ \\
\hline D-Lactose $\alpha$ & $\mathrm{CH}^{2}$ & 3.59 & 73.7 & - \\
\hline D-Lactose $\alpha$ & $\mathrm{CH}$ & 3.96 & 72.5 & - \\
\hline D-Lactose $\alpha$ & $\mathrm{CH}$ & 3.66 & 76.8 & - \\
\hline D-Lactose $\alpha$ & $\mathrm{CH}$ & 3.84 & 73.8 & - \\
\hline D-Lactose $\beta$ & $\mathrm{CH}$ & 4.67 & 98.2 & $q$ \\
\hline D-Lactose $\beta$ & $\mathrm{CH}$ & 3.66 & 80.5 & - \\
\hline D-Lactose $\beta$ & $\mathrm{CH}$ & 3.29 & 76.2 & q \\
\hline D-Lactose $\beta$ & $1 / 2 \mathrm{CH}_{2}$ & 3.96 & 62.4 & $\mathrm{q}$ \\
\hline D-Lactose $\beta$ & $\mathrm{CH}$ & 3.60 & 77.3 & $q$ \\
\hline D-Lactose $\beta$ & $1 / 2 \mathrm{CH}_{2}$ & 3.81 & 62.4 & - \\
\hline D-Lactose $\beta$ & $\mathrm{CH}$ & 3.84 & 73.8 & - \\
\hline 3-Methylhistidine & $\alpha-\mathrm{CH}$ & 3.97 & 56.0 & - \\
\hline 3-Methylhistidine & $\beta-\mathrm{CH}_{2}$ & $3.30 / 2.25$ & 27.5 & $q$ \\
\hline 3-Methylhistidine & $\mathrm{CH}_{3}$ & 3.74 & 34.7 & $\mathrm{q}$ \\
\hline 3-Methylhistidine & $\delta-\mathrm{CH}$ & 7.14 & 125.7 & $\mathrm{q}$ \\
\hline 3-Methylhistidine & $\varepsilon-\mathrm{CH}$ & 8.09 & 140.6 & 1 \\
\hline$N$-Acetyl-carbohydrates & $\mathrm{CH}_{3}$ & 2.05 & 23.8 & $\mathrm{q}$ \\
\hline Phosphocholine & $\mathrm{CH}_{2}$ & 4.16 & 60.2 & $\mathrm{q}$ \\
\hline Phosphocholine & $\mathrm{CH}_{2}$ & 3.58 & 68.5 & $\mathrm{q}$ \\
\hline Phosphocholine & $3 * \mathrm{CH}_{3}$ & 3.18 & 56.1 & $\underline{-}$ \\
\hline Phosphocreatine & $\mathrm{CH}_{3}$ & 3.03 & 39.1 & $q$ \\
\hline Phosphocreatine & $\mathrm{CH}_{2}$ & 3.93 & 56.1 & $\mathrm{q}$ \\
\hline Taurine & $\mathrm{S}-\mathrm{CH}_{2}$ & 3.43 & 38.2 & $\mathrm{q}$ \\
\hline Taurine & $\mathrm{N}-\mathrm{CH}_{2}$ & 3.27 & 50.2 & $\mathrm{q}$ \\
\hline Trimethylamine-N-oxide & $\mathrm{CH}_{3}$ & 3.27 & 62.1 & $q$ \\
\hline
\end{tabular}

${ }^{1}$ Groups (e.g., $\mathrm{CH}, \mathrm{CH}_{2}, \mathrm{CH}_{3}$ ) used for compound identification and quantification are marked with q. Unambiguously identified groups that could not be used for quantification because of signal overlap are marked with a dash. 
ing spectra were acquired. The concentration range was extended to $166 \mathrm{mmol} / \mathrm{L}$ for lactose. The number of signals that were used for compound identification is presented in Table 3 and equals the number of measured calibration curves. However, because of overlap of signals even in the 2D spectra, only a subset of these signals could be used for quantification. Because of metabolites inconsistently present in milk, a few rare cases of additional overlap were observed, leading to drastically increased integral values for certain metabolite signals. As a consequence, outlier signals that deviated from the median of the signals of a compound by more than $50 \%$ were automatically excluded from further analysis. Following absolute quantification of individual signals, the corresponding concentration ranges for each metabolite were calculated.

The limit of detection (LOD), which was defined as a signal:noise ratio of 3.5 for the strongest signal of a compound, was obtained from the calibration samples (Table 3). The lowest 3 points of each calibration curve were measured in triplicate, and the corresponding relative standard deviations were determined to calculate the lower limits of quantification (LLOQ). Following the recommendation of FDA (2001), the LLOQ was defined as the concentration value that could be determined with a relative standard deviation $<20 \%$. The LOD and LLOQ obtained were functions of the NMR acquisition time. Therefore, lower values may be obtained by increasing the acquisition time.

\section{GC-MS of AA and of BHBA, Glucose, and Citrate Cycle Intermediates}

Quantitative analysis of AA in $20-\mu \mathrm{L}$ aliquots of skim milk was completed using GC-MS after derivatization with propyl chloroformate as described previously (Kaspar et al., 2008).

Ten-microliter aliquots of defatted milk were extracted with $50 \mu \mathrm{L}$ of methanol containing the stable isotope labeled extraction standards $\left[2,2,4,4-{ }^{2} \mathrm{H}_{4}\right]$ citrate, $\left[\mathrm{U}_{-}{ }^{13} \mathrm{C}\right]$ fumarate, $\left[\mathrm{U}^{13}{ }^{13} \mathrm{C}\right]$ glucose, $\left[\mathrm{U}^{13} \mathrm{C}\right] \mathrm{BHBA},\left[\mathrm{U}_{-}{ }^{13} \mathrm{C}\right]$ lactate, $\left[2,3,3-{ }^{2} \mathrm{H}_{3}\right]$ malate, $\left[\mathrm{U}_{-}{ }^{13} \mathrm{C}\right]$ pyruvate, $\left[\mathrm{U}_{-}{ }^{2} \mathrm{H}\right]$ succinate, and $\left[{ }^{2} \mathrm{H}_{7}\right]$ trans-cinnamate, and unlabeled norvaline, which had been purchased from either Cambridge Isotopes Laboratories Inc. (Andover, MA), CDN Isotopes Inc. (Quebec, Canada), or Sigma-Aldrich. The purity of all extraction standards exceeded $98 \%$. The addition of stable isotope internal standards leads to more precise quantification, because their properties are chemically equivalent to their corresponding metabolites, but they are distinguishable from the naturally occurring metabolites by a separate mass. Samples were centrifuged at $4^{\circ} \mathrm{C}$ and $3,375 \times g$ for $5 \mathrm{~min}$, and the supernatant was transferred into a $2-\mathrm{mL}$ glass vial with a $0.2-\mathrm{mL}$ glass insert. Pellets were reextracted twice with $50 \mu \mathrm{L}$ of methanol. The extracts were combined and evaporated (CombiDancer, Hettich AG, Bäch, Switzerland) to complete dryness. The vials were then closed with magnetic crimp caps for automated handling by the autosampler and placed in a cooled $\left(5^{\circ} \mathrm{C}\right)$ tray. Prior to derivatization, $10 \mu \mathrm{L}$ of internal standard solution containing odd-numbered, saturated straight-chain fatty acids (C9-C19; Sigma-Aldrich) at a concentration of $1 \mathrm{mmol} / \mathrm{L}$ were added to the sample residue. Then, $50 \mu \mathrm{L}$ of $10 \mathrm{mg} / \mathrm{mL}$ of methoxylamine hydrochloride in pyridine (Sigma-Aldrich) was added and incubated at $60^{\circ} \mathrm{C}$ for $60 \mathrm{~min}$, followed by $50 \mu \mathrm{L}$ of $N$-methyl-N-trifluoroacetamide (Macherey-Nagel, Dueren, Germany) for $60 \mathrm{~min}$ at $60^{\circ} \mathrm{C}$. Samples were thoroughly mixed during incubation in the agitator.

A Pegasus GC time-of-flight MS instrument (Leco Corp., St. Joseph, MI) was used for the quantitative analysis of BHBA, glucose, and intermediates of the citrate cycle. The instrument configuration comprised a model 6890 GC (Agilent Technologies, Santa Clara, CA) coupled to a fast-scanning time-of-flight mass spectrometer providing unit mass resolution, a PTV injector (Gerstel, Mülheim an der Ruhr, Germany), and a MPS-2 Prepstation sample robot (Gerstel) for automated sample derivatization and handling. The robot was equipped with 2 agitators for sample incubation and 2 syringes of different volumes. A $10-\mu \mathrm{L}$ syringe was used for internal standard addition and sample injection, whereas a $250-\mu \mathrm{L}$ syringe was used for adding reagents. In between the adding steps, the syringes were washed 3 times with isooctane. A RXI-5 MS column $(30 \mathrm{~m} \times 0.25 \mathrm{~mm}$ i.d. $\times 0.25 \mu \mathrm{m}$ film thickness; Restek, GmbH, Bad Homburg, Germany) coupled to a RTX-1701 column $(2 \mathrm{~m} \times 0.1 \mathrm{~mm}$ i.d. $\times 0.1 \mu \mathrm{m}$ film thickness; Restek) and equipped with a deactivated precolumn $(5 \mathrm{~m} \times 0.25 \mathrm{~mm}$ i.d.; Agilent $)$ was used. The oven temperature was initially held at $50^{\circ} \mathrm{C}$ for $0.2 \mathrm{~min}$, raised at $8^{\circ} \mathrm{C} / \mathrm{min}$ to $265^{\circ} \mathrm{C}$, and held for $10 \mathrm{~min}$. The column flow was $1 \mathrm{~mL}$ of $\mathrm{He} / \mathrm{min}$. A sample volume of $1.5 \mu \mathrm{L}$ was injected in splitless mode. The temperature of the PTV injector was set at $50^{\circ} \mathrm{C}$ for $0.5 \mathrm{~min}$ and increased at $12^{\circ} \mathrm{C} / \mathrm{s}$ to $250^{\circ} \mathrm{C}$. A chemically inert Siltec liner (Gerstel) was used. The mass spectra were acquired over a mass:charge ratio $(\mathrm{m} / \mathrm{z})$ of 40 to 600 at a rate of 50 spectra/s, and the solvent delay was set to 8 min.

Calibration was completed using metabolite standard solutions in methanol. In this step, $100 \mu \mathrm{L}$ of different calibration concentrations were transferred into a glass vial with glass insert, and $10 \mu \mathrm{L}$ of the surrogate solution containing stable isotope labeled $\left[2,2,4,4-{ }^{2} \mathrm{H}_{4}\right]$ citrate, $\left[\mathrm{U}_{-}{ }^{13} \mathrm{C}\right]$ fumarate, $\left[\mathrm{U}_{-}{ }^{13} \mathrm{C}\right]$ glucose, $\left[\mathrm{U}_{-}{ }^{13} \mathrm{C}\right] \mathrm{BHBA}$, $\left[\mathrm{U}_{-}{ }^{13} \mathrm{C}\right]$ lactate, $\quad\left[2,3,3-{ }^{2} \mathrm{H}_{3}\right]$ malate, $\quad\left[\mathrm{U}_{-}{ }^{13} \mathrm{C}\right]$ pyruvate, 
Table 3. Metabolites quantified by nuclear magnetic resonance (NMR) and gas chromatography-mass spectrometry (GC-MS $)^{1}$

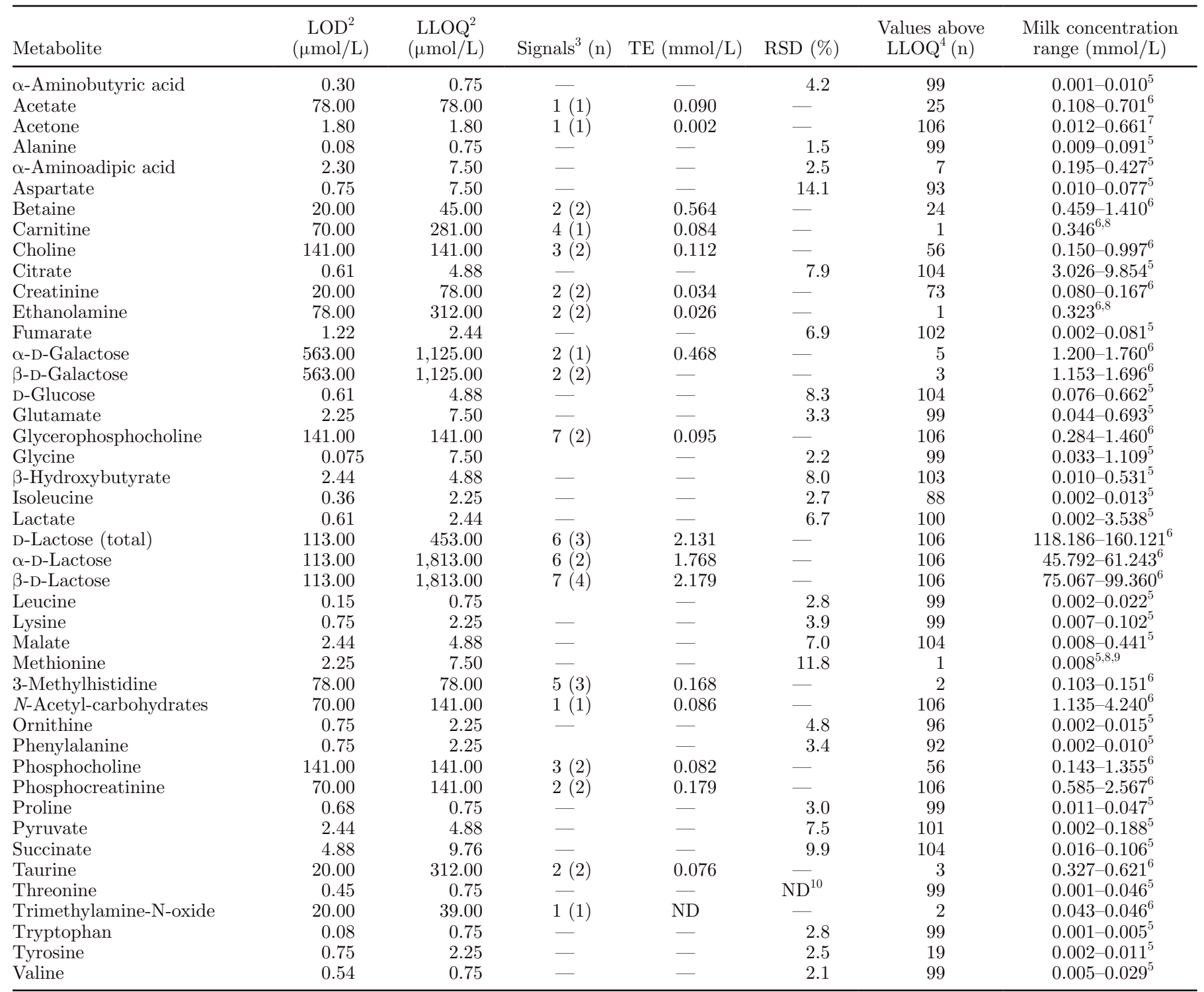

${ }^{1} \mathrm{LOD}=$ molar limits of detection; LLOQ = lower limits of quantification; signals $(\mathrm{n})=$ number of signals used for metabolite assignment and quantification; TE = technical error estimated from duplicate measurements (NMR); RSD = relative standard deviations from calibration replicates (GC-MS).

${ }^{2}$ LOD and LLOQ values for the compounds quantified by NMR spectroscopy are dependent on the total acquisition time of an NMR spectrum. The corresponding acquisition times for 1-dimensional ${ }^{1} \mathrm{H}$ and 2-dimensional ${ }^{1} \mathrm{H}-{ }^{13} \mathrm{C}$ heteronuclear single quantum coherence NMR spectra were 15 and $56 \mathrm{~min}$, respectively. Note that the different compounds were simultaneously measured in a single spectrum. Therefore, an increase in acquisition time would decrease the LOD and LLOQ values of all metabolites analyzed by NMR.

${ }^{3}$ Number of groups (e.g., $\mathrm{CH}, \mathrm{CH}_{2}, \mathrm{CH}_{3}$ ) used for NMR-based metabolite identification and quantification (the latter in parentheses).

${ }^{4}$ The number of values above LLOQ varies from metabolite to metabolite because individual LLOQ were determined for each metabolite; also, the abundance of the various metabolites greatly varies. In total, 106 milk samples were analyzed, which results in a maximum number of 106 values that could be obtained for a single metabolite.

${ }^{5}$ Concentrations obtained from GC-MS spectra.

${ }^{6}$ Concentrations obtained from ${ }^{1} \mathrm{H}^{-13} \mathrm{C}$ 2-dimensional heteronuclear single quantum coherence NMR spectra.

${ }^{7}$ Concentrations obtained from ${ }^{1} \mathrm{H}$ 1-dimensional NMR spectra.

${ }^{8}$ Only 1 value detected.

${ }^{9}$ Measured in colostrum milk sample obtained from farm 2 .

${ }^{10} \mathrm{ND}=$ not determined. 


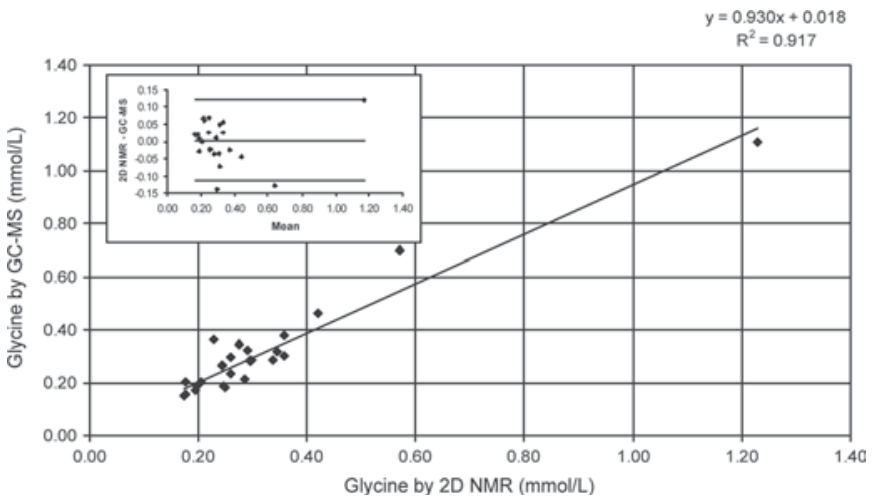

Figure 1. Linear regression and Bland-Altman plot of concentrations $(\mathrm{mmol} / \mathrm{L})$ of glycine in milk specimens measured by 2-dimensional nuclear magnetic resonance (2D NMR) and gas chromatographymass spectrometry (GC-MS).

$\left[\mathrm{U}_{-}{ }^{2} \mathrm{H}\right]$ succinate, $\left[{ }^{2} \mathrm{H}_{7}\right]$ trans-cinnamate, and unlabeled norvaline $(1 \mathrm{mmol} / \mathrm{L}$ each $)$ were added. The standards were dried and derivatized as described. Over a concentration range of 0.5 to $500 \mu \mathrm{mol} / \mathrm{L}, 12$ calibration points were generated.

\section{Statistics}

For calculation of technical errors, all NMR measurements were completed in duplicate and the technical errors (TE) were calculated according to the following equation:

$$
\mathrm{TE}=\sqrt{\frac{\sum_{i=1}^{N}\left(x_{i, 1}-x_{i, 2}\right)^{2}}{2 N}},
$$

where $N$ is the number of samples that were measured in duplicate and $x_{i, 1}$ and $x_{i, 2}$ are the first and second measurement of a specific sample, respectively.

Pearson correlation coefficients were calculated using Excel 2007 (Microsoft, Redmond, Washington) and conservative global limits above 0.5 and below -0.5 were used to label observed correlations as significant. At the $5 \%$ level, statistical significance is generally reached with these r-values for a sample size less than 20. Although for some metabolites up to 106 measurements (Table 3) above the individual LLOQ were available, for others this number was considerably smaller. Therefore, these global limits for r-value ensured that only significant correlations were marked as such (Supplemental Figure 1; http://www.journalofdairyscience.org/).

A Bland-Altman plot (Bland and Altman, 1986) is inserted in Figure 1. In this graphical model, also known as Tukey mean difference plot, the difference $y_{n}$ between data obtained by 2 methods $\left(y_{n}=x_{0}-y_{0}\right)$ is plotted for each sample against the average $x_{n}$ of the 2 methods $\left[x_{n}=\left(x_{\mathrm{o}}+y_{\mathrm{o}}\right) / 2\right]$. Bland-Altman plots are well suited to analyze the agreement between 2 experimental methods.

\section{RESULTS AND DISCUSSION}

\section{$L O D$ and $L L O Q$}

Molar LOD and LLOQ were determined for both NMR and MS. As described in the experimental section, LOD for the $2 \mathrm{D}{ }^{1} \mathrm{H}-{ }^{13} \mathrm{C}$ HSQC and $1 \mathrm{D}{ }^{1} \mathrm{H}$ spectra were calculated from calibration standards (Table 3). The LOD ranged for the 2D spectra from 20 to $563 \mu \mathrm{mol} / \mathrm{L}$ at a signal:noise level of 3.5. The lowest LOD were obtained for methyl group containing analytes, such as betaine, where the protons of the methyl group(s) give rise to a single signal in the corresponding $2 \mathrm{D}$ NMR spectra or for compounds that were identified from 1D spectra. One-dimensional spectra were used for quantification of acetone and BHBA; hence, considerably lower LOD of $1.8 \mu \mathrm{mol} / \mathrm{L}$ were obtained.

The LLOQ values for the individual compounds are given in Table 3. The lowest LLOQ values were obtained for compounds with multiple methyl groups or for compounds that were identified from 1D spectra. The LLOQ values obtained for $2 \mathrm{D}$ spectra of pure compounds were generally higher than those obtained for 1D spectra. However, in a previous contribution (Gronwald et al., 2008) it was shown that in real biological samples more accurate results are obtained by the use of 2D spectra. From the calibration curves, it was demonstrated that measurements remained linear up to concentrations as high as $166 \mathrm{mmol} / \mathrm{L}$ for lactose without readjusting the receiver gain.

In MS, the quantification range was determined by the LLOQ and upper limits of quantification, which were defined as the lowest and highest points, respectively, of the calibration curve, with an accuracy between 80 and $120 \%$. This is in agreement with FDA (2001). For MS, the LOD were defined as the concentration producing a signal:noise ratio of at least $3: 1$. The concentrations reported in Table 3 were calculated from the analysis of $20-\mu \mathrm{L}$ aliquots and the lowest obtained LOD amounted to $0.08 \mathrm{mmol} / \mathrm{L}$, corresponding to an absolute injection amount of $15 \mathrm{fmol}$.

\section{D NMR Versus MS}

An important prerequisite for the combined analysis of data from both NMR and MS is to demonstrate agreement of the 2 methods. Of the 44 milk metabolites analyzed, 23 were measured by NMR and 25 by GC- 

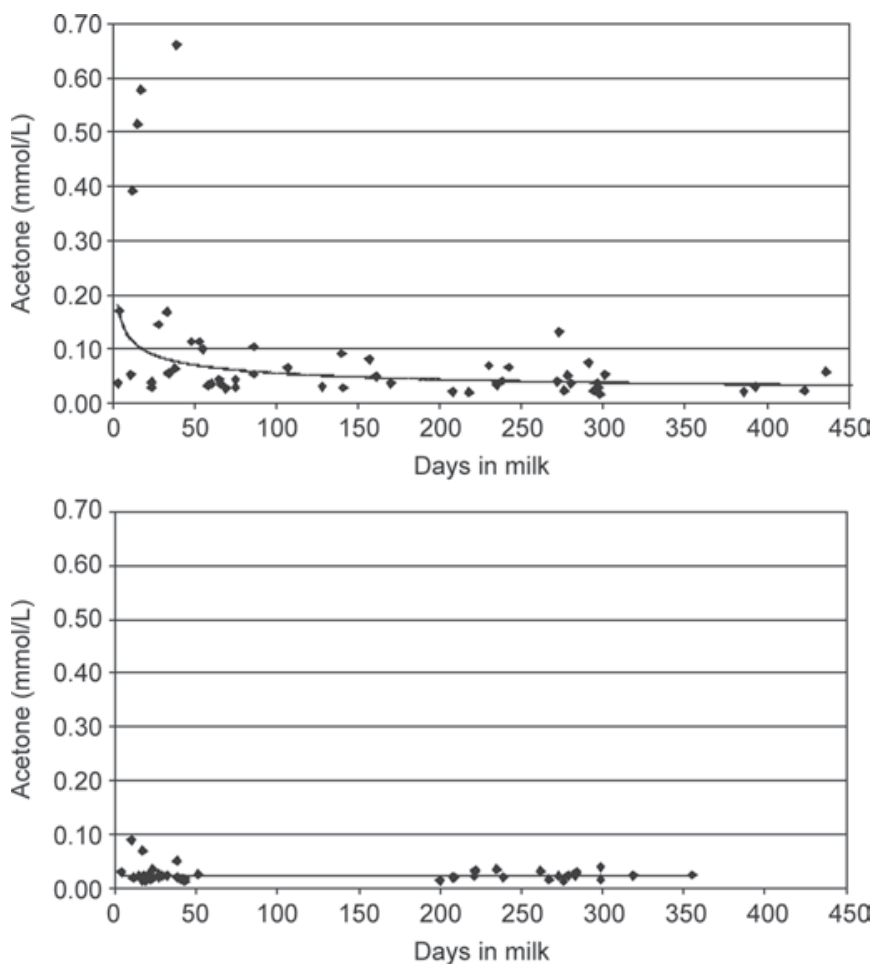

Figure 2. Correlation between lactation day and acetone concentration (mmol/L) for milk specimens from farm 1 (top) and farm 2 (bottom) as measured by 1-dimensional nuclear magnetic resonance. To clarify the general trend of the data, a potential regression line was added.

MS as either their propyl chloroformate (AA) or methoximated and trimethylsilylated derivatives (remaining analytes; Table 3). Alanine, glycine, BHBA, and lactate were analyzed by both NMR and GC-MS to check for data agreement between the methods. A comparison of the corresponding NMR and GC-MS data for Gly is shown in Figure 1. The high $\mathrm{R}^{2}$-value of 0.92 indicates that both methods allowed the precise determination of Gly over the entire concentration range of 0.033 to 1.109 $\mathrm{mmol} / \mathrm{L}$. The slope of the linear regression curve of 0.93 and the positive $\mathrm{y}$-axis intercept of $0.018 \mathrm{mmol} / \mathrm{L}$ confirmed good concordance between NMR and GCMS data. The Bland-Altman plot shown as an insert in Figure 1 reveals an even smaller mean difference of 0.04 $\mathrm{mmol} / \mathrm{L}$ between the 2D NMR and GC-MS measurements. Similar results were obtained for Ala, BHBA, and lactate (data not shown). In summary, NMR and MS data may be safely combined for statistical data analysis.

\section{Analysis of Milk Metabolites}

The observed concentration range for each of the 44 analyzed milk metabolites is given in Table 3 . The ranges were calculated over all milk samples from both farms, and, because for some metabolites concentration values above their LLOQ were not available in all samples, no average values and standard deviations are given. As expected from previous literature, concentrations of lactose in milk fell within a relatively narrow concentration range of 118 to $160 \mathrm{mmol} / \mathrm{L}(40.4-54.8$ $\mathrm{mg} / \mathrm{mL}$; Roginski et al., 2004). In contrast, metabolites such as phosphocholine showed an almost 10-fold difference between the lowest $(0.143 \mathrm{mmol} / \mathrm{L})$ and the highest $(1.355 \mathrm{mmol} / \mathrm{L})$ concentration observed. The AA in milk are absorbed from blood, but undergo extensive synthesis and degradation in the mammary gland (Bequette et al., 1998). The pathways of metabolic transformation are the same or similar as found in other tissues. In dairy ruminants producing large quantities of milk and milk protein, Met (Pinotti et al., 2002) or a combination of Met and Lys (Schwab et al., 1992) have been reported to be the first limiting AA for milk protein synthesis. Methionine is required for transmethylation reactions and milk protein synthesis and may stimulate milk and milk fat production by enhancing lipoprotein synthesis, gluconeogenesis, and provision of methyl groups for phospholipid synthesis
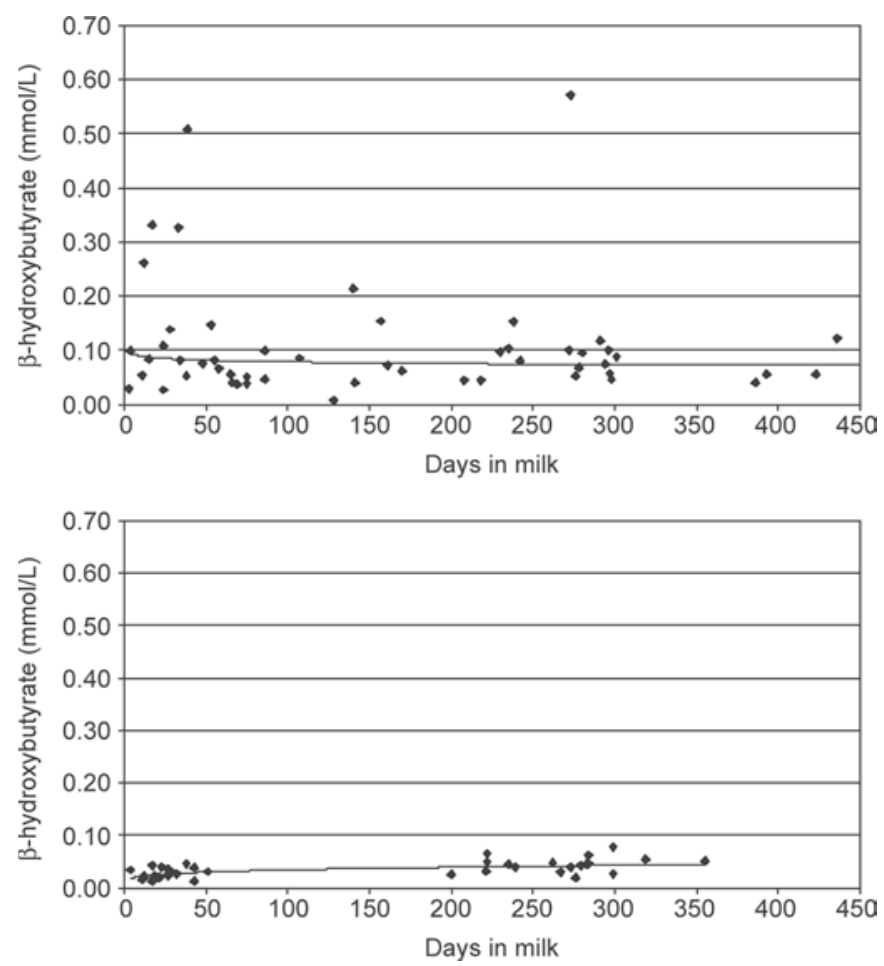

Figure 3. Correlation between lactation day and BHBA concentration $(\mathrm{mmol} / \mathrm{L})$ for milk specimens from farm 1 (top) and farm 2 (bottom) as measured by 1-dimensional nuclear magnetic resonance. To clarify the general trend of the data, a potential regression line was added. 
in the liver and sulfur groups for the synthesis of Cys (Bequette et al., 1998). Methionine was detected in only a single sample of colostrum that was not included in the study. These data support the hypothesis that the total uptake of Met probably balances with its output in milk protein (Bequette et al., 1998). In regard to AA that limit milk protein synthesis, it has been recognized that they vary depending on the quality and quantity of AA in basal diets. As a result, different amounts and proportions of AA are absorbed from duodenal ingesta (Rulquin et al., 1993). High correlation between Lys and protein content (Supplemental Figure 1) throughout lactation $(\mathrm{r}=0.57)$ also reflects the limiting nature of this AA for protein production.

\section{Investigation of Metabolic Status During Early Lactation}

An important objective of this study was the measurement of metabolites that might serve as indicators of a metabolic imbalance during early lactation. Known markers for the status of energy metabolism are acetone and BHBA (Enjalbert et al., 2001; Duffield et al., 2009). The top part of Figure 2 shows the correlation between lactation day and observed acetone concentration for farm 1. Some cows yielded significantly increased acetone values above threshold concentration for detection of subclinical ketosis of $0.16 \mathrm{mmol} / \mathrm{L}$ during the first days of lactation (Enjalbert et al., 2001). Drastically lower acetone values of about $0.04 \mathrm{mmol} / \mathrm{L}$ were found for other cows at a similar lactation stage. Generally, acetone values decreased during the first 70 $\mathrm{d}$ of lactation and remained fairly constant thereafter. The bottom part of Figure 2 shows the correlation between acetone concentration and lactation day for farm 2. Here, only slightly increased acetone concentrations of up to $0.088 \mathrm{mmol} / \mathrm{L}$ were observed for a few cows during the first $70 \mathrm{~d}$ of lactation. Generally, the observed acetone concentrations were lower for cows from farm 2 than for farm 1. During late lactation, average values of $0.024 \mathrm{mmol} / \mathrm{L}$ were observed for cows from farm 2 and the corresponding values for cows from farm 1 were about $0.030 \mathrm{mmol} / \mathrm{L}$.

Similar but less pronounced effects were observed for BHBA (Figure 3). In the early lactation period, increased values above the threshold concentration of $70 \mu \mathrm{mol} / \mathrm{L}$ for the detection of subclinical ketosis (Enjalbert et al., 2001) were found in a subset of cows from farm 1 . Note that for $1 \mathrm{cow}$, increased BHBA values were obtained at a time point in late lactation, indicating a possible health problem. In contrast to farm 1, cows from farm 2 showed constant BHBA concentrations over the entire lactation period. Acetone and BHBA showed a good correlation over all cows, with a Pearson correlation coefficient of 0.69 (Supplemental Figure 1). This is in agreement with a published correlation of milk acetone to BHBA of 0.68 (Enjalbert et al., 2001).

Baticz et al. (2002) suggested measurements of citrate as a marker of energy status in the dairy cow, being correlated with ketones in milk and de novo fatty acid synthesis. This suggestion is supported by our data with an observed Pearson correlation coefficient of 0.45 between citrate and acetone in milk and a corresponding correlation coefficient of 0.39 between citrate and BHBA. Milk citrate concentration has been found to vary widely throughout lactation (Garnsworthy et al., 2006) depending on nutrition and season (Holt and Muir, 1979). Generally, it is higher in early lactation and decreases gradually as lactation progresses (Konar et al, 1971). In the study reported here, citrate remained fairly constant throughout lactation (average \pm SD: $6.270 \pm 1.311 \mathrm{mmol} / \mathrm{L}$ ), but concentrations that were determined by GC-MS were higher than those obtained by NMR in commercial milk in a previous study (Hu et al., 2007). In this context, it should be noted that we also determined citrate by 2D NMR. However, so-called spike in experiments where known amounts of citrate were added to milk showed that, for this metabolite, the GC-MS measurements were more accurate. One
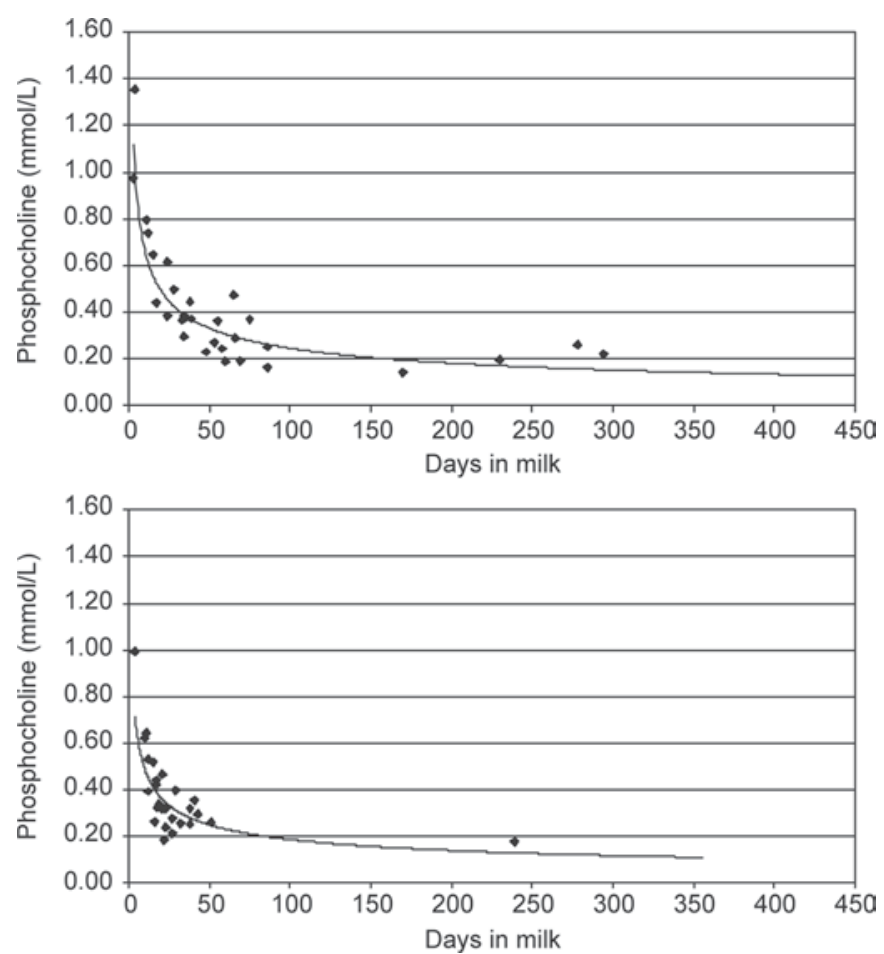

Figure 4. Correlation between lactation day and phosphocholine concentration (mmol/L) for milk specimens from farm 1 (top) and farm 2 (bottom) as measured by 2-dimensional nuclear magnetic resonance. To clarify the general trend of the data, a potential regression line was added. 

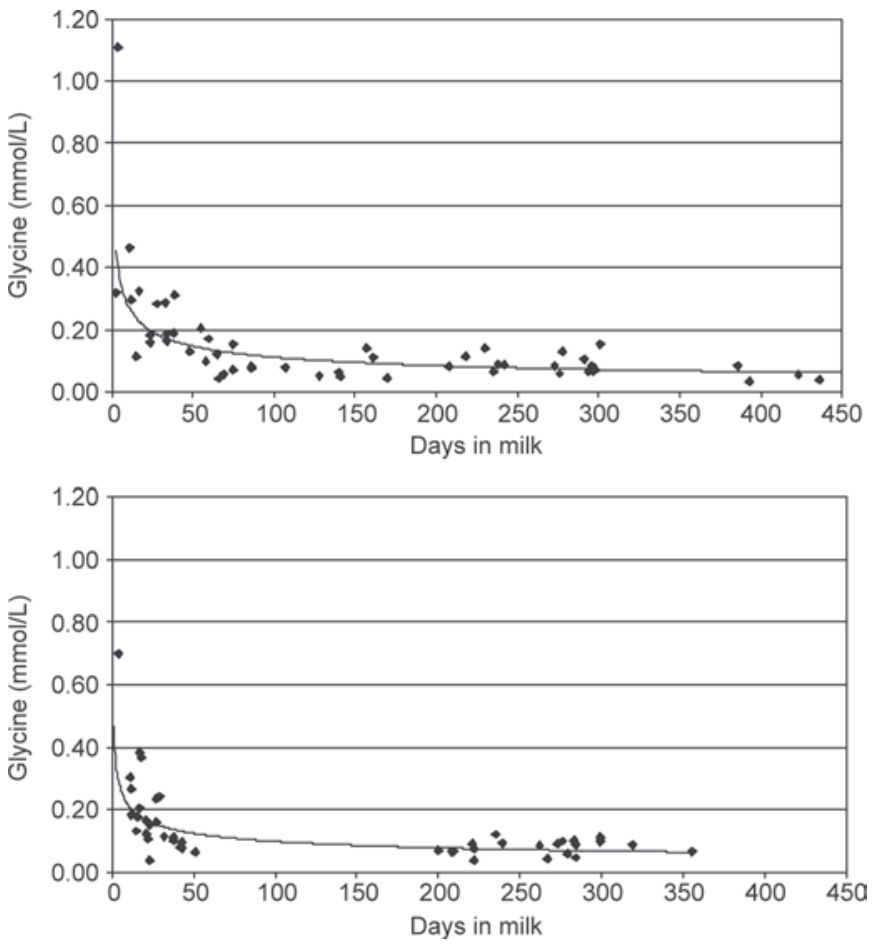

Figure 5. Correlation between lactation day and glycine concentration (mmol/L) for milk specimens from farm 1 (top) and farm 2 (bottom) as measured by gas chromatography-mass spectrometry. To clarify the general trend of the data, a potential regression line was added.

likely explanation for the observed discrepancies to the NMR measurements is that milk citrate is located in part in the colloidal phase of milk and, therefore, could not be determined by NMR.

An analyte that has been linked to udder health problems is lactate. However, the data presented here suggest no correlation between SCC and lactate. In addition, changes in pyruvate concentrations and, particularly, lactate dehydrogenase activity have been previously associated with mammary infections (Chagunda et al., 2006). However, as for lactate, no correlation can be observed between pyruvate and SCC (Supplemental Figure 1). In contrast, a high correlation $(\mathrm{r}=0.87)$ between lactate and pyruvate that is its precursor in the glycolytic pathway was observed.

Significant correlation coefficients were observed between the branched-chain AA (BCAA) Ile, Leu, and Val. They are all catabolized by mammary cells to yield organic acids (oxo and iso acids, propionate, acetate, and citrate), carbon skeletons for synthesis of nonessential AA (Glu and Asp), and $\mathrm{CO}_{2}$. The branchedchain keto acid dehydrogenase that is shared by all the BCAA and Met catalyzes the rate-limiting step of the BCAA catabolic pathway (Harper et al., 1984).
The analysis of specific metabolites throughout lactation showed increased phosphocholine concentrations for all cows in early lactation (Figure 4), with a maximum of 1.355 and $0.991 \mathrm{mmol} / \mathrm{L}$ for cows from farm 1 and farm 2, respectively. Around d 70 of lactation, phosphocholine concentrations had decreased to approximately $0.25 \mathrm{mmol} / \mathrm{L}$ at both farms and remained relatively constant thereafter. Note that in the last lactation third, phosphocholine concentrations had decreased below the LLOQ in some cows. Phosphocholine is a precursor of choline and serves as its storage form within the cytosol. It showed a slightly negative correlation with DIM $(\mathrm{r}=-0.42)$. For choline, somewhat lower values were obtained in early lactation than in the last lactation third (data not shown). These findings agree only partly with those in human milk, where a distinct decrease during lactation in the concentrations of phosphocholine and free choline was found, but only for the first $90 \mathrm{~d}$ and $3 \mathrm{wk}$, respectively, after birth (Holmes et al., 2000). Choline in milk can be derived by active uptake from maternal circulation (Chao et al., 1988) and from de novo synthesis within the mammary gland (Zeisel et al., 1988).
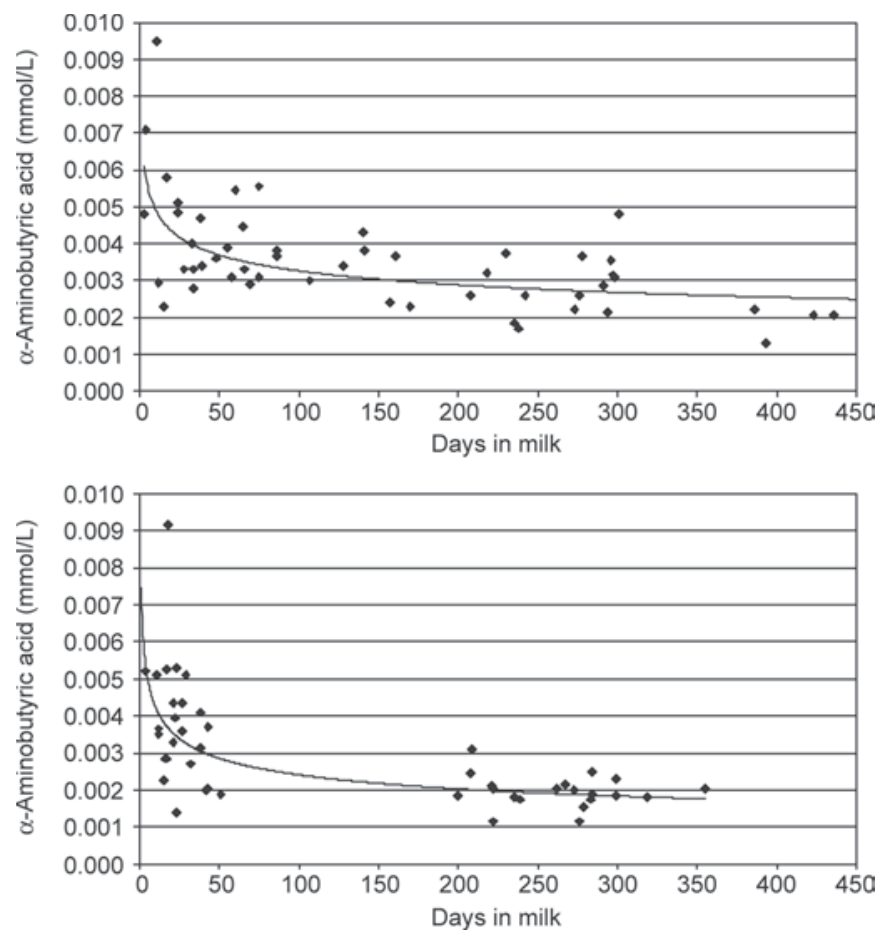

Figure 6. Correlation between lactation day and $\alpha$-aminobutyric acid concentration (mmol/L) for milk specimens from farm 1 (top) and farm 2 (bottom) as measured by gas chromatography-mass spectrometry. To clarify the general trend of the data, a potential regression line was added. 
Higher needs of dairy cows for the limiting AA Met for transmethylation reactions and milk protein synthesis lead to altered methyl group metabolism (Pinotti et al., 2002). Choline plays an important role in the metabolic pathways of methyl groups via the tetrahydrofolate system, which might explain the correlation between milk protein content and free choline in milk $(\mathrm{r}=0.50)$. Furthermore, it has been demonstrated previously that abomasal infusion of choline and administration or feeding of rumen-protected choline increases milk protein content (Sharma and Erdman, 1988; Erdman and Sharma, 1991).

Similar to phosphocholine, a decrease in concentration over the first $70 \mathrm{~d}$ of lactation was observed for Gly (Figure 5). Starting at maximum concentrations of 1.109 and $0.700 \mathrm{mmol} / \mathrm{L}$ for farm 1 and farm 2, respectively, Gly concentrations dropped to approximately $0.070 \mathrm{mmol} / \mathrm{L}$ for both farms. In addition, a high Pearson correlation coefficient of 0.81 was observed between Gly and phosphocholine (Supplemental Figure 1), with the latter serving as a precursor of Gly. The increased concentrations of phosphocholine (Figure 4) and Gly (Figure 5) found in early lactation imply an increased Gly metabolism during that period. This effect is more pronounced for the higher producing animals on farm 1 (Figure 4 and 5). It has been shown that infusion of glucagon increases free Gly concentration in milk (Bobe et al., 2009). Concomitantly, above-average milk production was associated with above-average glucagon concentrations (Herbein et al., 1985).

Quite interesting was the positive Pearson correlation coefficient of 0.66 between $\alpha$-aminobutyric acid and Gly. The former is a member of the $\alpha$-ketobutyrate metabolism; in humans, increased plasma concentrations of $\alpha$-aminobutyric acid have been observed in the early phase of prolonged starvation. Starvation of humans is somewhat similar to the negative energy balance present in the early phase of bovine lactation. Therefore, it is not unexpected that increased concentrations of $\alpha$-aminobutyric acid have been observed in early lactation. In addition, $\alpha$-aminobutyric acid is quite sensitive to altered systemic insulin concentrations (Felig et al., 1969). As can be seen in Figure 6, increased concentrations of up to $0.01 \mathrm{mmol} / \mathrm{L}$ were observed for $\alpha$-aminobutyric acid during the first third of lactation, whereas in the second and last lactation third, average values of approx. $0.003 \mathrm{mmol} / \mathrm{L}$ were seen. This effect was evident only in animals from farm 1 . No clear trends between lactation day and metabolite concentrations were observed for the remaining metabolites.

The quantification of $N$-acetyl-carbohydrates $(N$ acetyl-lactosamine and $N$-acetyl-glucosamine) by NMR was described previously and values were in a similar range as those presented here (Hu et al., 2007). N-
Acetyllactosamine is found in many glycoproteins and glycolipids. That might explain the correlation between $\mathrm{N}$-acetylcarbohydrates and protein content in milk $(\mathrm{r}=$ 0.57 ) and between other membrane-associated analytes such as phosphocholine $(\mathrm{r}=0.57)$ and betaine $(\mathrm{r}=$ $0.74)$.

\section{Interherd Comparison}

Systematic differences between the 2 investigated herds independent of metabolic stress in early lactation were analyzed. To that end, 30 selected metabolites were selected, for which a sufficient number of measurements were available for the last lactation third. The median concentrations of most metabolites were higher in milk samples from Brown Swiss cows than from Simmental cows. A typical example was the higher concentrations of $\alpha$-aminobutyric acid observed for Brown Swiss in comparison with Simmental cows (average \pm SD: $2.92 \pm$ $0.82 \mu \mathrm{mol} / \mathrm{L}$ vs. $1.97 \pm 0.46 \mu \mathrm{mol} / \mathrm{L})$. The corresponding $P$-value of $3.8 \mathrm{E}^{-4}$ shows that for $\alpha$-aminobutyric acid, the 2 groups were significantly different. Because of the limited literature on $\alpha$-aminobutyric acid in cows, this finding needs further elucidation in future studies. A metabolite that should remain almost constant is lactose and, as expected, almost no difference was observed between the 2 breeds. Another interesting metabolite was ornithine; in contrast with most other metabolites, significantly $\left(P=4.1 \mathrm{E}^{-12}\right)$ higher average values were obtained for Simmental cows (0.006 $\pm 0.002 \mathrm{mmol} / \mathrm{L})$ than for Brown Swiss cows $(0.004 \pm$ $0.001 \mathrm{mmol} / \mathrm{L}$ ). Ornithine acts as a carbon precursor of proline, a nitrogen precursor of several nonessential AA, and a precursor of polyamines (Mepham, 1982). The metabolic differences observed between the herds are most likely associated with differences in breed and feed management.

\section{CONCLUSIONS}

The analysis of numerous milk metabolites by GCMS and NMR revealed large differences in concentrations of known biomarkers of energy metabolism such as acetone and BHBA during early lactation, indicating that individual animals cope very differently with the metabolic stress in this period. This was particularly true for high-producing animals that yielded highly discrepant values for these markers. Further metabolomic analyses might help to select cows that cope well with the metabolic stress of early lactation without a priori knowledge. Novel correlations were observed between metabolites such as $\alpha$-aminobutyric acid and Gly. One avenue for gaining additional knowledge in future inves- 
tigations is the combination of metabolomic analyses as performed here and genetic studies.

\section{ACKNOWLEDGMENTS}

The work of the staff at the Veitshof (Freising, Germany) and at Bavarian State Research Centre for Agriculture (Poing-Grub, Germany) is gratefully acknowledged. We thank Sebastian Miemczyk (Institute of Functional Genomics, University of Regensburg, Regensburg, Germany) for help in the sample preparation. This study was funded by the Bavarian Genome Network (BayGene), Munich, Germany and the German Federal Ministry of Education and Research.

\section{REFERENCES}

Almstetter, M. F., I. J. Appel, M. A. Gruber, C. Lottaz, B. Timischl, R. Spang, K. Dettmer, and P. J. Oefner. 2009. Integrative normalization and comparitive analysis for metabolic fingerprinting by comprehensive two-dimensional gas chromatography-time-offlight mass spectrometry. Anal. Chem. 81:5731-5739.

Baticz, O., S. Tomoskozi, L. Vida, and T. Gaal. 2002. Relationship between concentration of citrate and ketone bodies in cow's milk. Acta Vet. Hung. 50:253-261.

Belloque, J., and M. Ramos. 2002. Determination of the casein content in bovine milk by ${ }^{31} \mathrm{P}$ NMR. J. Dairy Res. 69:411-418.

Bequette, B. J., F. R. Backwell, and L. A. Crompton. 1998. Current concepts of amino acid and protein metabolism in the mammary gland of the lactating ruminant. J. Dairy Sci. 81:2540-2559.

Bland, J. M., and D. G. Altman. 1986. Statistical methods for assessing the agreement between two methods of clinical measurement. Lancet 327:307-310.

Blouin, J. P., J. F. Bernier, C. K. Reynolds, G. E. Lobley, P. Dubreuil, and H. Lapierre. 2002. Effect of supply of metabolizable protein on spanchnic fluxes of nutrients and hormones in lactating dairy cows. J. Dairy Sci. 85:2618-2630.

Bobe, G., A. R. Hippen, P. She, G. L. Lindberg, J. W. Young, and D. C. Beitz. 2009. Effects of glucagon infusions on protein and amino acid composition of milk from dairy cows. J. Dairy Sci. 92:130-138.

Boudonck, K. J., M. W. Mitchell, J. Wulff, and J. A. Ryals. 2009. Characterization of the biochemical variability in bovine milk using metabolomics. Metabolomics 5:375-386. doi:10.1007/ s11306-009-0160-8

Chagunda, M. G., T. Larsen, M. Bjerring, and K. L. Ingvartsen. 2006. L-lactate dehydrogenase and N-acetyl-beta-D-glucosaminidase activities in bovine milk as indicators of non-specific mastitis. J. Dairy Res. 73:431-440.

Chao, C. K., E. A. Pomfret, and S. H. Zeisel. 1988. Uptake of choline by rat mammary-gland epithelial-cells. Biochem. J. 254:33-38.

Duffield, T. F., K. D. Lissemore, B. W. McBride, and K. E. Leslie. 2009. Impact of hyperketonemia in early lactation dairy cows on health and production. J. Dairy Sci. 92:571-580.

Enjalbert, F., M. C. Nicot, C. Bayourthe, and R. Moncoulon. 2001. Ketone bodies in milk and blood of dairy cows: Relationship between concentrations and utilization for detection of subclinical ketosis. J. Dairy Sci. 84:583-589.

Erdman, R. A., and B. K. Sharma. 1991. Effect of dietary rumenprotected choline in lactating dairy cows. J. Dairy Sci. 74:16411647.

FDA. 2001. Guidance for Industry Bioanalytical Method Validation. Center for Drug Evaluation and Research, U.S. Department of Health and Human Services, Rockville, MD.
Felig, P., O. E. Owen, J. Wahren, and G. F. Cahill. 1969. Amino acid metabolism during prolonged starvation. J. Clin. Invest. 48:584594.

Garnsworthy, P. C., L. L. Masson, A. L. Lock, and T. T. Mottram. 2006. Variation of milk citrate with stage of lactation and de novo fatty acid synthesis in dairy cows. J. Dairy Sci. 89:1604-1612.

Geishauser, T., K. Leslie, J. Tenhag, and A. Bashiri. 2000. Evaluation of eight cow-side ketone tests in milk for detection of subclinical ketosis in dairy cows. J. Dairy Sci. 83:296-299.

Gronwald, W., M. S. Klein, H. Kaspar, S. Fagerer, N. Nürnberger, K. Dettmer, T. Bertsch, and P. J. Oefner. 2008. Urinary metabolite quantification employing 2D NMR spectroscopy. Anal. Chem. 80:9288-9297.

Harper, A. E., R. H. Miller, and K. P. Block. 1984. Branched-chain amino acid metabolism. Annu. Rev. Nutr. 4:409-454.

Herbein, J. H., R. J. Aiello, L. I. Eckler, R. E. Pearson, and R. M. Akers. 1985. Glucagon, insulin, growth hormone, and glucose concentrations in blood plasma of lactating dairy cows. J. Dairy Sci. 68:320-325.

Holmes, H. C., G. J. A. I. Snodgrass, and R. A. Iles. 2000. Changes in the choline content of human breast milk in the first 3 weeks after birth. Eur. J. Pediatr. 159:198-204.

Holt, C., and D. D. Muir. 1979. Inorganic constituents of milk: I. Correlation of soluble calcium with citrate in bovine milk. J. Dairy Res. 46:433-439.

Hu, F., K. Furihata, Y. Kato, and M. Tanokura. 2007. Nondestructive quantification of organic compounds in whole milk without pretreatment by two-dimensional NMR spectroscopy. J. Agric. Food Chem. 55:4307-4311.

ISO. 2005. EN ISO/IEC 17025:2005. General requirements for the competence of testing and calibration laboratories. CENELEC, Brussels, Belgium.

Kaspar, H., K. Dettmer, W. Gronwald, and P. J. Oefner. 2008. Automated GC-MS analysis of free amino acids in biological fluids. J. Chromatogr. B Analyt. Technol. Biomed. Life Sci. 870:222-232.

Konar, A., P. C. Thomas, and J. A. F. Rook. 1971. Concentrations of some water-soluble constituents in milks of cows, sows, ewes and goats. J. Dairy Res. 38:333-341.

Lindon, J. C., E. Holmes, and J. K. Nicholson. 2006. Metabonomics techniques and applications to pharmaceutical research \& development. Pharm. Res. 23:1075-1088.

Mepham, T. B. 1982. Amino acid utilization by lactating mammary gland. J. Dairy Sci. 65:287-298.

Pinotti, L., A. Baldi, and V. Dell'Orto. 2002. Comparative mammalian choline metabolism with emphasis on the high-yielding dairy cow. Nutr. Res. Rev. 15:315-331.

Pyorala, S. 2003. Indicators of inflammation in the diagnosis of mastitis. Vet. Res. 34:565-578.

Roginski, H., J. W. Fuquay, and P. F. Fox, ed. 2004. Encyclopedia of Dairy Sciences. Academic Press Inc., London, UK.

Rulquin, H., P. M. Pisulewski, R. Verite, and J. Guinard. 1993. Milkproduction and composition as a function of postruminal lysine and methionine supply-A nutrient-response approach. Livest. Prod. Sci. 37:69-90.

Schwab, C. G., C. K. Bozak, N. L. Whitehouse, and M. M. A. Mesbah. 1992. Amino acid limitation and flow to duodenum at 4 stages of lactation. 1. Sequence of lysine and methionine limitation. J. Dairy Sci. 75:3486-3502.

Sharma, B. K., and R. A. Erdman. 1988. Abomasal infusion of choline and methionine with or without 2-amino-2-methyl-1-propanol for lactating dairy cows. J. Dairy Sci. 71:2406-2411.

Toso, B., G. Procida, and B. Steffanon. 2002. Determination of volatile compounds in cows' milk using headspace GC-MS. J. Dairy Res. 69:569-577.

Wishart, D. S. 2008. Quantitative metabolomics using NMR. Trends Analyt. Chem. 27:228-237.

Zeisel, S. H., E. Yang, C. K. Chao, J. K. Blusztain, and E. A. Pomfret. 1988. Mammary gland can accumulate choline from blood and can synthesize choline de novo. FASEB J. 2:A650. 